Published in final edited form as:

J Exp Psychol Hum Percept Perform. 2013 April ; 39(2): 494-509. doi:10.1037/a0029400.

\title{
The development of individuation in autism
}

\author{
Kirsten O'Hearn ${ }^{1}$, Steven Franconeri ${ }^{2}$, Catherine Wright ${ }^{1}$, Nancy Minshew ${ }^{1,3}$, and Beatriz \\ Luna ${ }^{1}$ \\ ${ }^{1}$ Department of Psychiatry, University of Pittsburgh \\ ${ }^{2}$ Department of Psychology, Northwestern University \\ ${ }^{3}$ Department of Neurology, University of Pittsburgh
}

\begin{abstract}
Evidence suggests that people with autism use holistic information differently than typical adults. The current studies examine this possibility by investigating how core visual processes that contribute to holistic processing - individuation and element grouping - develop in participants with autism and typically developing (TD) participants matched for age, IQ and gender. Individuation refers to the ability to 'see' up to 4 elements simultaneously; grouping these elements can change the number of elements that are rapidly apprehended. We examined these core processes using two well-established paradigms, rapid enumeration and multiple object tracking (MOT). In both tasks, a performance limit of about 4 elements in adulthood is thought to reflect individuation capacity. Participants with autism has a smaller individuation capacity than TD controls, regardless of whether they were enumerating static elements or tracking moving ones. To manipulate holistic information and individuation performance, we grouped the elements into a design or had elements move together. Participants with autism were affected to a similar degree as TD participants by the holistic information, whether the manipulation helped or hurt performance, consistent with evidence that some types of gestalt/grouping information are processed typically in autism. There was substantial development in autism from childhood to adolescence, but not from adolescence to adulthood, a pattern distinct from TD participants. These results provide important information about core visual processes in autism, as well as insight into the architecture of vision (e.g., individuation appears distinct from visual strengths in autism, such as visual search, despite similarities).
\end{abstract}

\section{Keywords}

autism; subitizing; global-local; individuation; holistic; configural; grouping; gestalt; indexing

\section{Introduction}

People with autism display a unique style of visual processing (Dakin \& Frith, 2005; Simmons et al., 2009). For typically developing (TD) adults, global or holistic information (Navon, 1977) - or the overall gist of a visual scene (Rensink, 2002) - often takes precedence over local information. However, people with autism seem to access and focus more easily on local information (about or embedded in individual objects) than on global configuration (Behrmann et al., 2006a; Dakin \& Frith, 2005; Scherf et al., 2008; Simmons et

Corresponding author: Kirsten O'Hearn Laboratory of Neurocognitive Development University of Pittsburgh Medical Center 121 Meyran Ave., 112 Loeffler Bldg. Pittsburgh, PA 15213 Phone: 412-512-7727 FAX: 412-246-6161 ohearnk@ upmc.edu.

Preliminary results were presented at the Annual Meeting of the Society for Neuroscience, November 2008 and the International Meeting for Autism Research, May 2010. 
al., 2009). This visual style has led to theories of autism such as Enhanced Perceptual Functioning or EPF (Mottron et al., 2006), which emphasizes an inherent bias for local information, and Weak Central Coherence or WCC (Happe, 1999), which additionally specifies a deficit in processing global configuration. Both of these theories highlight the local bias in visual processing, which appears to lead to superior performance on some tasks (Shah \& Frith, 1983b; O'Riordan \& Plaisted, 2001b). WCC integrates this local bias with a deficit in processing global configuration in autism, potentially affecting important visual skills that require the representation of multiple elements (e.g., face recognition, interpretation of social scenes). While these theories suggest that limitations in holistic processing in autism reflect basic perceptual differences, the actual processes underlying this 'local bias' are unclear.

In this paper, we examine two basic perceptual processes that contribute to holistic processing typically - individuation of multiple elements and sensitivity to element grouping - to test if they differ in autism. Individuation refers to the ability to apprehend a small number of elements simultaneously; seeing these elements in parallel may allow us to rapidly integrate them into a holistic representation, regardless of their arrangement. This is distinct from sensitivity to element grouping, which we examine in individuation paradigms though it is important in many visual tasks. Element grouping also supports holistic processing, but generally does so on the basis of previous knowledge or gestalt principles (e.g., continuity, symmetry, common fate). To examine these interacting processes, we used two well-established tasks: rapid enumeration and multiple object tracking (MOT). We characterized the developmental trajectory of these processes to see whether group differences are stable over time, or change with development.

\section{Rapid enumeration}

In rapid enumeration (Experiment 1), participants are asked to make rapid, exact counts of a set of elements. For small collections ( 1 to 4 elements), response times are fast and almost constant, suggesting that up to 4 individuals elements can be counted in parallel (Mandler \& Shebo, 1982b; Revkin et al., 2008; Trick \& Pylyshyn, 1994), a skill called 'subitizing' (Kaufman et al., 1949). Subitizing is thought to reflect the adult's ability to individuate approximately four elements at once. In contrast, response times for larger collections of elements (5 to $8+$ elements) are slower, with reaction time (RT) and errors increasing systematically with each additional element. This behavioral pattern suggests that these higher numbers of elements require serial processing, which takes longer with each additional element. The longer RT is likely due to the need to shift attention to subsets of objects while marking previously counted subsets.

If people with autism individuate fewer elements simultaneously than TD participants, they might switch to a serial process for lower numbers of elements, resulting in a smaller subitizing range. Gagnon and colleagues (2004) found this pattern, despite their original hypothesis that those with autism would perform better than TD adults due to their associations with mathematical skill. The participants with autism appeared to use a serial process with fewer elements - around 3 - than TD participants. While suggestive, these results were limited because the groups were not directly compared, the subitizing range was not explicitly quantified, and the effect was generally not robust. These issues are addressed in the current study.

While Gagnon's work suggests that individuation is a 'global' visual process impacted by autism, individuation could also be considered a 'local' process and individuals with autism may be better at individuating multiple elements. The 'local bias' in autism might reflect that attention is allocated across individual elements, allowing those with autism to encode more elements at once. This would explain the 'better than typical' abilities in autism on tasks 
such as visual search (O'Riordan \& Plaisted, 2001) or block construction (Shah \& Frith, 1993): more individual elements within the display are individuated, and therefore represented, simultaneously. Some recent evidence is consistent with this view. Remington and colleagues (2009) found that adults with autism could effectively process a higher perceptual load than TD adults. Thus, individuals with autism may have enhanced parallel processing (Mottron et al., 2006), leading to the ability to individuate (and subitize) more elements at once.

\section{Multiple object tracking}

To provide converging evidence on individuation capacity, we also used a multiple object tracking (MOT) task (Experiment 2), which to our knowledge has not been examined in autism. MOT also controlled for a potential confound of the rapid enumeration task participants with autism may choose to count earlier than TD participants. In MOT, participants are asked to track the locations of a set of target objects moving among a set of distracter objects with identical features, so that each individual target must be continuously tracked in order to distinguish it from distractor objects(Pylyshyn \& Storm, 1988). MOT studies reveal that typical observers can track a maximum of 4 objects under most conditions, and more in carefully designed displays that maximize inter-object distance (Alvarez \& Franconeri, 2007). The common limit of about 4-objects suggests that both subitizing and MOT may be sensitive to a shared performance limit on parallel individuation (Pylyshyn, 2000). This possibility is supported by training studies (Green \& Bavelier, 2006) and the results from a dual task study with both MOT and rapid enumeration - for each object enumerated, one fewer object could be tracked (Chesney \& Haladjian, 2011).

\section{Element grouping}

Because the goal of the present study is to explore how differences in individuation might contribute to a 'local bias' in visual processing in people with autism, it is critical to simultaneously study visual grouping, a phenomenon that goes hand-in-hand with individuation. This is particularly important because whether individuation is considered a local or a global process may differ on the basis of whether the elements are grouped -individuation might function as a 'local' process without grouping, but might be a 'global' process under conditions of grouping. Thus, we manipulated the parameters of both of these tasks, rapid enumeration and MOT, to examine grouping processes. The grouping either helps or hurts performance typically, by facilitating individuation or making it more difficult because elements that need to be differentiated are grouped together.

For the rapid enumeration task, in the non-grouped or original condition, the elements were randomly located. In the 'helping performance' grouped condition, elements were grouped into canonical shapes (dice patterns) that improve performance. Previous work indicates that participants enumerate elements in a dice pattern more rapidly, especially with a greater number of elements (5 or 6), than they do without the pattern (Mandler \& Shebo, 1982). This presumably reflects matching the pattern with long-term memory representations, though the systematic arrangement of elements may in and of itself aid enumeration (e.g., it might facilitate subitizing of subgroups of 2 or 3 objects at once). In the 'hurting performance' grouped condition, the elements were concentrically grouped into a single 'stack' in a manner that impairs performance, presumably by causing participants to see all the elements as a single object. To accurately enumerate even just a few elements in this arrangement requires serial attention to segregate each object within the 'group' (often with one by one counting), making enumeration drastically slower even with fewer elements (Trick \& Pylyshyn, 1994). 
For the MOT task, in the non-grouped, original condition, the elements moved independently and randomly around the display. In the grouped conditions, each element was paired with another element using motion - namely common fate, the fact the elements were moving together. In the 'helping performance' grouped condition, these groups consisted of target-target and distractor-distractor pairs. This grouping improves performance by allowing participants to effectively track two target 'groups' instead of four target 'objects' (Scholl et al., 2001). In the 'hurting performance' grouped condition, each group consisted of a target-distractor pair, which impairs performance by dragging the participant's focus from the single target objects to the level of groups (the target-distractor pair), but the groups do not differentiate between targets and distractors (Scholl et al., 2001).

\section{Predictions}

We hypothesized that those with autism would be less sensitive to holistic or global information evident when the elements were grouped, regardless of whether it help or hurt performance. This hypothesis was generated because individuals with autism appear less sensitive to the types of information manipulated in the grouping conditions, namely prior knowledge (i.e., less sensitive to the overall picture in the embedded figures test; Shah \& Frith, 1983) and gestalt information (proximity, closure and similarity; Brosnan et al., 2004; similarity only in Farran \& Brosnan, 2011). In the grouped conditions in rapid enumeration, knowledge influenced performance, either by a dice pattern which allows participants to enumerate the display on the basis of a known pattern, or by concentric squares in which the elements are automatically grouped into a single unit. In the grouped conditions in MOT, gestalt information - common motion - again influenced performance. While common motion per se has not been previously tested in autism, we hypothesized that those with autism would be less sensitive to common motion, consistent with the results with other types of gestalt information in autism. There is also evidence that people with autism are less sensitive to motion coherence (Milne et al., 2002) and biological motion (Annaz et al., 2010). Since both of these tasks clearly require sensitivity to common motion, these results also support the idea that those with autism would not be as influenced by common motion in the MOT task as TD participants

The predictions for individuation performance were less obvious. One possible scenario is that the participants with autism individuate objects typically or even better than TD participants, reflecting their skill on tasks such as visual search (O'Riordan \& Plaisted, 2001; O'Riordan, 2004; discussed earlier on p. 5). However, on the basis of Gagnon et al. (2004) and evidence that those with autism encode fewer elements in complex visual displays (Fletcher-Watson et al., 2006; Loth et al., 2008; O'Hearn et al., 2011b), we hypothesized instead that those with autism would individuate fewer objects than TD participants, in addition to being less sensitive to their arrangement. If so, two distinct basic perceptual processes related to holistic processing would be atypical in autism, compounding the differences in how adults with autism "see" visual scenes with multiple elements.

We also hypothesized that these differences might become more striking with age. Previous work indicates that participants with autism may not undergo the developmental improvement that occurs typically during adolescence, especially in encoding all the elements in a scene (O'Hearn et al., 2010b; see also Scherf et al., 2008; Kuschner et al., 2009). This developmental perspective highlights that group differences may not be stable across age in a neurodevelopmental disorder such as autism, in which maturation itself is atypical and skills build upon previous achievements. 


\section{Experiment 1: Rapid Enumeration}

\section{Methods}

Participants-Participants included 39 well-characterized participants with autism (36 M, $4 \mathrm{~F}$ ), and $39 \mathrm{TD}$ participants matched individually to the participants with autism on age (within $1.5 \mathrm{y}$ in children, $3.5 \mathrm{y}$ in adults), IQ (12 points) and gender. These groups included 9 children ( $9-12$ years old), 15 adolescents (13-17 years old) and 15 adults (18- 29 years old). These age ranges were chosen because they represent meaningful stages of development. Participants with Pervasive Developmental Disorder- Not otherwise Specified (PDD-NOS) or Asperger's syndrome (i.e., no language delay evident) were excluded, as were those with full-scale IQ scores $<80$ on the Wechsler Abbreviated Scale of Intelligence (Wechsler, 1999) or those known to have an associated disorder such as tuberous sclerosis or fragile-X syndrome. The Autism Diagnostic Interview-Revised (ADI; Lord et al., 1994) and the Autism Diagnostic Observation Schedule-General (ADOS; Lord et al., 2000), as well as expert clinical opinion, were used to diagnose autism (see Table 1 for ADI and ADOS scores and demographic information). Typically developing (TD) participants were healthy, with no history of head trauma, birth complications, seizures, or psychiatric disorder. Informed consent and assent was obtained from all participants and/or their legal guardians prior to the study, which was approved by the Institutional Review Board at the University of Pittsburgh.

Procedure-All participants performed the tasks in a single session, using two laptop computers. The session took place in a quiet office. Whether rapid enumeration or MOT came first was counterbalanced between subjects and matched across groups. In rapid enumeration, the random location condition was always first in case the session could not be finished, because it was critical for interpretation of the other two conditions. Whether the dice or concentric condition came next was counterbalanced between subjects and matched across groups. Both laptops were placed on a desk 25" in front of the participant's face. Each rapid enumeration condition took about 10 minutes to complete (30 minutes for all three conditions).

Condition 1: random locations: The display was presented on a Dell Inspiron E1405, and programed in visual basic. On the laptop screen, there was a rectangle, 5.25" high and 6.75" wide, on which the experimental display was projected. The experimenter pushed a button to start the trial when the participant was ready. When the trial started, 1 to 8 dark gray squares ( $80 \%$ black) appeared on a light gray (20\% black, both with equal amounts of red, blue, green, in Microsoft standard colors) background (Figure 1A). The squares and background were gray to minimize visual aftereffects. The squares were randomly placed - with each trial unique - with the constraint that their centers be at least 3.1 degrees-of-visual-angle (dva) apart. They were randomly sized from three possible sizes ( $0.85 \mathrm{dva} ; 1.3 \mathrm{dva} ; 1.8$ $\mathrm{dva}$ ), to avoid the possibility that the number task could be correctly answered on the basis of another factor, like density. Each number of items (1 through 8) was presented 6 times in a random order, making 48 trials. The order of trials, and location of squares, was randomly generated for a given participant, but then it was labeled with a number so it could be the same across individuals with autism and the control who matched them on age, IQ and gender. The participants did at least 6 practice trials before the task; these were repeated again if the experimenter thought it was needed.

Once the participant indicated they were ready, the experimenter pressed a button that started the trial, and a fixation cross came on for $500 \mathrm{~ms}$. Both this cross and the experimenter alerted the participant that it was time to attend closely to the display. Once the fixation cross disappeared, the gray squares appeared and stayed on until the microphone 
recorded a voice signal. This display was presented for as long as it took the participant to answer. When they answered, the gray squares were replaced with a marbled black and white background (again to minimize after effects). An answer box popped up, and the experimenter typed in the participant's response. If the experimenter felt that the program had been triggered in error - i.e., by a loud sound outside the room or an "ummm" - they hit the 'enter' key without typing a number, and that trial was not used but instead repeated at the end of the program. This did not happen frequently, as the participants were explicitly told not to say anything but the answer. The instructions were: "When I hit the button, some squares are going to appear on the screen. Your job is to tell the computer how many there were. The computer will be listening for you and it only wants to hear numbers so be careful and don't say things like "um". Sometimes you will just know how many squares there are really fast and if that happens, I want you to tell the computer the answer as fast as you can! Sometimes you won't know the answer so quick and then I want you to count in your head and tell me the answer when you know it. I want you to do your best and try to tell me the exact number each time. Ready to try?"

Reaction time of verbal responses was measured via microphone (Abrams \& Jennings, 2004). Participants were encouraged to be fast but completely accurate, in order to minimize differences in the speed accuracy trade-off between groups. If participants made a mistake, they were reminded that accuracy was more important than speed, and the instructions were repeated.

Conditions $2 \&$ 3: grouping manipulations: The procedure in these separate conditions was the same as in Experiment 1, except for the arrangement of the displays (Figure 1B, C), the elements themselves in the concentric condition (Fig 1C) and that only 1 to 6 elements were tested. The Dice Condition was intended to enhance performance (especially with higher numbers of elements). It differed from the original version only in the placement of elements, which was no longer random but instead were standardized into classic dice patterns. The squares were still randomly chosen from three possible sizes.

The Concentric Condition was intended to undermine performance by requiring serial attention (Trick \& Pylyshyn, 1994). To do so, there were no longer constraints about the spacing between the elements; instead the elements were integrated into a single object by placing each square inside the other, with the squares described with the outside contour line only. The main location of the squares was still chosen randomly on each trial, but then the squares were placed inside each other. The sizes were randomly chosen from 8 possibilities (largest $=15 / 16 " ;$ smallest $=3 / 16 ")$. If, for instance, it was a 3 element trial, 3 squares from the 8 possibilities would be randomly chosen. This sampling eliminated a one to one correspondence between size/density and number. While it is a concern that participants could have used heuristics based on size or density to guess at number, we think that, since accuracy was stressed and there was no direct relationship, the majority of participants counted the squares instead of using heuristics.

Statistical analyses-Preliminary analyses analyzed accuracy, and indicated that the speed-accuracy trade-off differed slightly across groups in adulthood. Thus, a composite score of RT and accuracy (RT/accuracy) was formed, by dividing each participant's mean response time by the proportion correct. We call this measure "corrected RT" and it is the primary measure reported, although RT is reported when the two measures yielded distinct results. Townsend and Ashby (1983) also describe the same composite score, which they call the inverse processing efficiency score. A preliminary omnibus ANOVA was done on corrected RT, with Condition (random, dice, concentric) and Number (1 to 6) as within subjects factors, Group (autism, TD) and Age (child, adolescent, adult) as between subjects factors. This preliminary analysis indicated differences between the Conditions, as well as 
borderline interactions between Condition and Group, and Condition and Age. The main analyses then examined each condition separately, using the analyses described below. On ANOVAS, to control for violations of sphericity and differences in variability between groups, the Greenhouse-Geisser correction was used on the F statistic and Tamhane's t correction reported for the post-hoc comparisons of age.

Condition 1: random locations: To examine subitizing capacity, a bilinear function was fit to each individual using the corrected RT for 1 to 7 elements, with the constraint that the slope of the $1^{\text {st }}$ line (in the subitizing range) be no more than $250 \mathrm{~ms} / \mathrm{item}$ (Chi \& Klahr, 1975; Svenson \& Sjöberg, 1978) and no less than $-50 \mathrm{~ms} /$ item (which suggests anomalous data). We excluded 8 elements because we did not want to confound results with group differences in 'guessing end effect', when participants accurately identify the highest number of objects in the task (Piazza et al., 2003). The intercept between these lines that minimized error was considered the 'breakpoint', or subitizing capacity. The breakpoint provided an estimate of how many objects could be individuated, i.e., when parallel processing switches to serial counting. We also examined the slope in the subitizing ( 1 to 3 ) and counting (4 to 7 ) range. One adult with autism had reaction times that were more than $2.5 \mathrm{SD}$ slower than the mean for the autism group. To avoid biasing our results toward finding group differences on the basis of this individual, both he and his match were dropped from all analyses in the paper.

We then examined how the parallel and serial processes underlying enumeration were affected in autism, by forming a composite factor (Range) with two levels. The subitizing/ parallel range was the mean performance for 1,2 , and 3 elements, and the counting/serial range was mean performance for 5, 6, and 7 elements. We excluded 4 elements because this was the subitizing range for some participants and the counting range for others and 8 elements for the guessing end effect, described above.

Conditions 2 \& 3: Grouping manipulations: Our primary interest was how the dice and concentric conditions changed performance relative to the original enumeration task. Preliminary analyses indicated that participants with autism were slower than TD participants in all conditions, across the ages tested, as expected on the basis of previous evidence (Glazebrook et al., 2009; Luna et al., 2007). Group differences were analyzed using a repeated measures ANOVA, with Group (autism, TD) and Age (children, adolescents, adults) as between subject factors, and Number (1 to 6) and Condition (random, grouping manipulation) as within subject factors, to see whether these manipulations affected participants with autism differently than TD participants. Then, to examine how grouping manipulations affected performance over development typically and in autism, repeated measures ANOVAs analyzed performance in each group separately, with Number and Condition as a within subjects factor and Age as a between subject factor.

\section{Results}

\section{Preliminary analyses: Accuracy}

Condition 1: random: We expected accuracy to be almost perfect in all groups, since all participants were expert counters and accuracy was stressed. Indeed, all groups showed accuracy of $92 \%$ or better even in the counting range. What was surprising was that the lowest accuracy was evident in typical adults. ANOVAs of each age group separately revealed that adults with autism were more accurate than TD adults (main effect: $\mathrm{F}(1,28)=$ $7.91, \mathrm{p}=.009)$ in the counting range (Group $\times$ Range interaction; $F(1,28)=7.90, \mathrm{p}=.009$ ). $\mathrm{T}$-tests in the adult participants only, on each number separately, indicated that there were significant group differences with 6 and 7 items $(6$ items: $\mathrm{t}(28)=-2.32, \mathrm{p}=.03 ; 7$ items: $\mathrm{t}(28)=-2.22, \mathrm{p}=.04)$. There were no group differences on accuracy in either adolescents (p's 
$>.88$ ) or children (p's > .18). We controlled for this potential speed-accuracy trade-off between adults with and without autism by computing corrected RT score (RT/accuracy; O'Hearn et al., 2011; Townsend \& Ashby, 1983). If the results using RT differed from the corrected RT, both measures are reported.

Condition 2 \& 3: grouping: Preliminary analyses examined accuracy using an ANOVA with the factors of Group, Age and Number. In the Dice Condition, there was a trend for the participants with autism to make more mistakes than TD participants $(F(1,72)=3.86, p=$. 06); this was driven by group differences in the children (Group $\times$ Age group interaction: $\mathrm{F}(2,72)=3.26, \mathrm{p}=.04)$. These differences did not interact with Number, and all groups reached a mean accuracy of at least $97 \%$ accurate. In the Concentric condition, there were no main effects or interactions in accuracy, even though accuracy was much lower than in the other conditions (mean $>89 \%$ correct in all groups). Thus, though accuracy was high, there were minor differences in accuracy, suggesting a slightly different speed-accuracy trade-off between groups. Thus, analyses again used corrected RT.

Preliminary analyses: Omnibus ANOVA on Corrected RT-An initial omnibus repeated measures ANOVA, using the Greenhouse Geisser correction, with Number (1 to 6) and Condition (random, dice, concentric) as within subject variables, and Group and Age Group as between subjects variables revealed main effects for all factors (Number, $\mathrm{F}(1.13$, $81.004)=150.13, \mathrm{p}<.001 ;$ Condition, $\mathrm{F}(1.931,138.998)=97.31, \mathrm{p}<.001 ;$ Group, $\mathrm{F}(1,72)$ $=11.37, \mathrm{p}=.001 ;$ Age, $\mathrm{F}(2,72)=7.03, \mathrm{p}=.002$, with improvement from childhood to adolescence and childhood to adulthood ( $\mathrm{p}$ 's <.05) but not from adolescence to adulthood). Condition tended to interact with Group $(\mathrm{F}(1.125,81.004)=2.85, \mathrm{p}=.09)$ and Age $(\mathrm{F}(2.25$, $81.004)=2.61, \mathrm{p}=.07)$, and Number tended to interact with Group $(\mathrm{F}(1.93,138.99)=2.43$, $\mathrm{p}=.09)$.

\section{Main analyses: breakpoint, slope, RT on Condition 1, random locations}

Subitizing capacity/breakpoint (Figure 2): A bilinear function fit relatively well in all groups. A chi-square was used to examine Group and Age differences in the breakpoint. This analysis revealed a significant main effect of Group, using both corrected RT (chisquare(3) $=8.52, \mathrm{p}=.04$ ) or uncorrected RT (chi-square(4) $=13.71, \mathrm{p}=.008$, Cramer's V $=.42$ ), but no effect of Age nor an interaction. Overall, participants with autism had a smaller subitizing capacity than TD participants -- more likely to be 3 elements, while it was more often 4 elements in TD participants. When participants with autism and TD participants were examined using separate chi-squares, the breakpoint did not change with age in either group (i.e., no main effect of Age in autism: chi-square(6)=8.59, $\mathrm{p}=.20$; or in TD participants: chi-square( 4$)=1.49, \mathrm{p}=.83$ ).

Slope: The slopes in the subitizing range ( 1 to 3 objects) and the counting range (4 to 7 objects) were analyzed separately using ANOVAs with Group and Age as between subject factors. In the Subitizing range, there was a main effect of Age $(\mathrm{F}(2,72)=4.82, \mathrm{p}=.01)$ and Group $(\mathrm{F}(2,72)=4.45, \mathrm{p}=.04)$, which was moderated by an Age $\times$ Group interaction $(\mathrm{F}(2$, 72) $=3.96, \mathrm{p}=.02$ ). ANOVAs at each Age separately revealed that group differences in the subitizing slope were evident only in the children $(\mathrm{F}(1,16)=12.23, \mathrm{p}=.02$; other $\mathrm{p}$ 's $>.7)$. Children with autism had a steeper slope than TD children, suggesting they may have been counting even in the subitizing range.

Developmental analyses were done in each group separately to provide insight into the Age $\times$ Group interaction. In people with autism, the subitizing slope became flatter with age $(\mathrm{F}(2,36)=5.22, \mathrm{p}=.01$; corrected $\mathrm{RT}, \mathrm{F}(2,36)=6.36, \mathrm{p}=.004)$, with steeper slopes in children (uncorrected RT slope, $137 \mathrm{~ms} / \mathrm{obj}$ ) compared to adolescents ( $\mathrm{p}=.001 ; 59 \mathrm{~ms} / \mathrm{obj}$ ) and adults 
( $\mathrm{p}=.007 ; 64 \mathrm{~ms} / \mathrm{obj}$ ), who did not differ from each other ( $\mathrm{p}=.48$ ). In TD participants, the subitizing slope did not change with age (p's >.18; children $54 \mathrm{~ms} / \mathrm{obj}$; adolescents $78 \mathrm{~ms} /$ obj; adults $56 \mathrm{~ms} / \mathrm{obj}$ ).

In the Counting Range, uncorrected RT measures indicated main effects of both Group $(\mathrm{F}(1,72)=12.35, \mathrm{p}=.001)$ and Age $(\mathrm{F}(2,72)=4.04, \mathrm{p}=.02)$ on the slope but these were not evident with the corrected RT score (Group: $\mathrm{F}(1,72)=2.57$, $\mathrm{p}=.11$ : Age: $\mathrm{F}(2,72)=.18, \mathrm{p}=$. 84). Since these effects were no longer evident when group differences in speed accuracy trade-off were taken into account, this result reflects the distinct strategy chosen by TD adults who were faster but less accurate in the counting range than the other groups. There was no interaction between Group and Age on corrected RT or RT (TD children, $470 \mathrm{~ms} /$ obj, adolescents $412 \mathrm{~ms} / \mathrm{obj}$, adults $367 \mathrm{~ms} / \mathrm{obj}$ : autistic children $677 \mathrm{~ms} / \mathrm{obj}$, adolescents $526 \mathrm{~ms} / \mathrm{obj}$, adults $493 \mathrm{~ms} / \mathrm{obj}$ ).

RT: An ANOVA with Range (subitizing, counting) as a within subject factor and Group and Age as between subject factors was used. There were the expected main effects of Range (counting slower than subitizing: corrected RT F $(1,72)=4449.49, \mathrm{p}<.001$ ) and Group (participants with autism slower than TD participants: $\mathrm{F}(1,72)=16.58, \mathrm{p}=<.001)$. Group interacted with Range $(\mathrm{F}(1,72)=11.85, \mathrm{p}=.001)$, but this was mitigated by a borderline 3way interaction between Group, Range, and Age $(\mathrm{F}(2,72)=2.55, \mathrm{p}=.08)$, indicating that this interaction differed across Age. In children, deficits in autism were more pronounced in the counting than the subitizing range (Group, $\mathrm{F}(1,16)=9.64, \mathrm{p}=.007$; Group $\times$ Range, $\mathrm{F}(1,16)$ $=11.12, \mathrm{p}=.004)$. T-tests indicated that there was only a trend for differences in the subitizing range $(\mathrm{t}(16)=-1.93, \mathrm{p}=.07)$, with significant differences in the counting range $(\mathrm{t}(16)=-3.13, \mathrm{p}=.006)$. In adolescents, there was no main effect of Group $(\mathrm{F}(1,28)=2.50, \mathrm{p}=$. 13) nor interaction between Group and Range $(\mathrm{F}(1,28)=1.87, \mathrm{p}=.18)$, a pattern also evident in t-tests (subitizing: $\mathrm{t}(28)=-1.15, \mathrm{p}=.26$; counting: $\mathrm{t}(28)=-1.19, \mathrm{p}=.25$ ). In adults, there was a main effect of Group $(\mathrm{F}(1,28)=5.55, \mathrm{p}=.03)$ but no Group $\times$ Range interaction with the corrected RT $(\mathrm{F}(1,28)=1.82, \mathrm{p}=.19)$ though it was evident with uncorrected RT $(\mathrm{F}(1,28)$ $=4.86, \mathrm{p}=.04)$. $\mathrm{T}$-tests found that the pattern of group differences in adulthood tended toward the opposite of children, with RT in the subitizing range significantly impaired and the pattern in the counting range showing a strong trend (subitizing: $\mathrm{t}(14.8=-2.83, \mathrm{p}=.01$; counting: $\mathrm{t}(19.72=-2.06, \mathrm{p}=.053)$. Children with autism were more impaired in the counting than the subitizing range compared to TD children, this difference was not evident in older groups and there were no group differences in adolescence.

Development in each group was analyzed separately, again providing insight into the 3-way interaction between Group, Age and Range. TD participants displayed developmental improvement on RT in both ranges (main effect of Age; $\mathrm{F}(2,36)=5.27, \mathrm{p}=.01$, Age $\times$ Range; $\mathrm{F}(2,36)=2.39, \mathrm{p}=.11)$. Post-hoc analyses indicated that typical adults were faster than children $(\mathrm{p}=.03)$ and potentially adolescents $(\mathrm{p}=.10)$, with no differences between children and adolescents $(\mathrm{p}=.61)$. In people with autism, there was a main effect of Age $(\mathrm{F}(2,36)=4.92, \mathrm{p}=.01)$, but also an interaction between Age $\times$ Range $(\mathrm{F}(2,36)=6.37, \mathrm{p}=.004)$. In the counting range, participants with autism became faster with age $(\mathrm{F}(2,36)=5.71, \mathrm{p}=$. 007), with adolescents and adults (who did not differ, $\mathrm{p}=.99$ ) more rapid than children ( $\mathrm{p}$ 's $<$. 05). In the subitizing range, there was no developmental improvement in autism ( $\mathrm{F}(2$, 36) $=1.91, \mathrm{p}=.16$ ). Across typical development, the speed of both serial and parallel processes increased. However, only serial processes improved significantly with age in autism. 


\section{Main analyses: corrected RT on Conditions 2 (dice) \& 3 (concentric)}

Condition 2: Dice Condition (Figure 3A, Fig 3B for pattern across development): A repeated measures ANOVA was used, with the between subject factors of Group and Age, and within subject factors of Condition (random, dice) and Number. There was a main effect of Condition $(\mathrm{F}(1,72)=312.97, \mathrm{p}<.001)$, but also a significant Group $\times$ Condition interaction $(\mathrm{F}(1,72)=13.23, \mathrm{p}=.001)$. Grouping the elements helped participants with autism more than TD participants, counter to our expectations. There was the expected main effect of Group $(\mathrm{F}(1,72)=16.01, \mathrm{p}<.001)$, with the participants with autism performing more poorly overall, and of $\operatorname{Age}(\mathrm{F}(2,72)=7.39, \mathrm{p}=.001)$, with children performing more poorly than adolescents $(\mathrm{p}=.003)$ or adults $(\mathrm{p}<.001)$, but these factors did not interact. There was also a main effect of Number $(\mathrm{F}(2.04,146.58)=283.08, \mathrm{p}<.001)$, as well as interactions with Number $($ Number $\times$ Group $(F(2.04,146.58)=9.78, p<.001)$; Number $\times$ Age $(F(4.07$, $146.58)=5.32, \mathrm{p}<.001)$; Number $\times$ Group $\times$ Age $(F(4.07,146.58)=3.82, \mathrm{p}=.005)$; Condition $\times$ Number $(F(1.91,137.58)=243.56, p<.001)$; Condition $\times$ Number $\times$ Group $(\mathrm{F}(1.91,137.58)=4.65, \mathrm{p}=.01)$; Condition $\times$ Number $\times$ Age $(\mathrm{F}(3.82,137.58)=2.72, \mathrm{p}=.03)$. These effects of Number reflect that performance improved more at the higher numbers, and that this pattern was especially evident in the autism and the child groups. The dice pattern particularly improved performance at the high numbers because, in Condition 1 with random locations, participants were more likely to use one to one counting at the high numbers than the low numbers, leading to slow performance in Condition 1 and so the Dice pattern led to notable improvement.

When the TD participants only were analyzed, there was a main effect of Condition ( $\mathrm{F}(1$, $36)=287.05, \mathrm{p}<.001) ;$ Number $(\mathrm{F}(1.84,66.22)=153.09, \mathrm{p}<.001)$; and an interaction between Condition and Number $(\mathrm{F}(1.64,59.18)=150.42, \mathrm{p}<.001)$. The Dice Condition decreased RT, compared to Condition 1, and this was particularly true of higher numbers of elements. Paired t-tests indicated significant effects at every number (all p's <.001) except one element $(\mathrm{p}=.065)$. There was a main effect of Age $(\mathrm{F}(2,36)=4.65, \mathrm{p}=.016$ : the posthoc comparisons did not reach significance), but Age did not interact with Condition or Number.

In the participants with autism, there was a main effect of Condition $(\mathrm{F}(1,36)=137.35, \mathrm{p}<$. $001)$; Number $(\mathrm{F}(2.00,71.98)=143.47, \mathrm{p}<.001)$; and an interaction between Condition and Number $(\mathrm{F}(1.96,70.37)=112.39, \mathrm{p}<.001)$, reflecting the same pattern of results as TD participants. Paired t-tests showed improvement on all numbers (all p's $<.003$ ). There was a main effect of Age $(\mathrm{F}(2,36)=4.37, \mathrm{p}=.02)$, with significant improvement from childhood to adolescence $(\mathrm{p}=.04)$, with a trend from childhood to adulthood $(\mathrm{p}=.09)$ and no improvement from adolescence to adulthood $(\mathrm{p}=.99)$. Age interacted with Condition $(\mathrm{F}(2$, $36)=3.87, \mathrm{p}=.03)$ and Number $(\mathrm{F}(3.99,71.98)=6.13, \mathrm{p}<.001)$, with the Age $\times$ Condition $\times$ Number interaction showing a trend (corrected RT: $F(3.91,70.37)=2.93, \mathrm{p}=.06$; uncorrected RT: $\mathrm{F}(3.81,68.58)=3.04, \mathrm{p}=.03)$, reflecting that children improved more than the other ages in the Dice Condition and with higher numbers of elements.

\section{Condition 3: Concentric condition (Figure 3C, 3D for developmental pattern): An} ANOVA compared groups, with the between subject factors of Group and Age, and within subject factors of Condition (random, concentric) and Target Number. There was a main effect of Condition $(F(1,72)=88.52, p<.001)$, Number $(F(1.93,138.89)=92.92, p<.001)$, Group $(\mathrm{F}(1,72)=10.36, \mathrm{p}=.002)$, and of $\operatorname{Age}(\mathrm{F}(2,72)=6.49, \mathrm{p}=.003)$, with children performing more poorly than adolescents $(\mathrm{p}=.005)$ or adults $(\mathrm{p}=.001)$. As expected, the concentric manipulation made the task harder, as did higher numbers of elements; TD participants performed better than participants with autism, and adults and adolescents 
performed better than children. None of these factors interacted significantly. The concentric squares had a similar negative impact in participants with and without autism across age.

In the TD participants, there was a main effect of Condition $(F(1,36)=35.56, \mathrm{p}<.001)$; Number $(\mathrm{F}(1.39,41.02)=38.10, \mathrm{p}<.001)$; and an interaction between Condition and Number $(\mathrm{F}(1.12,40.23)=6.70, \mathrm{p}=.01)$. This reflected that impairments were more evident on the higher numbers in the Concentric condition. Paired t-tests showed impairment on all numbers (all p's $<.02$ ). There were no other significant effects, including no main effect of Age with corrected RT $(\mathrm{p}=.26)$, though there was with uncorrected RT $(\mathrm{F}(2,36)=4.25, \mathrm{p}=$. 02).

In the participants with autism, there was again a main effect of Condition $(\mathrm{F}(1,36)=54.03$, $\mathrm{p}<.001)$; Number $(\mathrm{F}(2.36,84.92)=56.31, \mathrm{p}<.001)$; and an interaction between Condition and Number $(\mathrm{F}(2.28,82.09)=10.86, \mathrm{p}<.001)$, the same pattern as in TD. Paired t-tests showed impairment on all numbers $(\mathrm{p}=.02)$. There was a main effect of Age $(\mathrm{F}(2,36)=$ $5.25, \mathrm{p}=.01$ ), with a trend for significant improvement from childhood to adulthood ( $\mathrm{p}=$. $054)$ but not from childhood to adolescence $(\mathrm{p}=.17)$ or adolescence to adulthood $(\mathrm{p}=.47)$. Age displayed a borderline interaction with Condition $(\mathrm{F}(2,36)=2.89, \mathrm{p}=.07)$, reflecting that children were more impacted by the concentric condition than older participants with autism.

\section{Experiment 2: Multiple Object Tracking (MOT)}

\section{Methods}

Participants-Each of the 78 participants mentioned in experiment 1 also completed experiment 2. See Experiment 1 for a description of the participants.

Procedure-The display on a Macintosh PowerBook G3 included 8 black squares outlined in white on a black background $(11.5 \times 8.5$ inches) (Figure 1B). Participants viewed an LCD monitor from a distance of approximately 25 inches. The screen (resolution $640 \times 480$ pixels, $60 \mathrm{~Hz}$ ) subtended approximately $28 \times 21$ degrees of visual angle (dva).

Displays were created and controlled using custom software written in C using the VisionShell libraries (Comtois, 2004). Before each trial, the squares (1.3 dva in diameter) were assigned random starting positions, with the constraint that objects could not touch each other or the screen boundaries. Motion paths were computed independently for each object with initial random starting directions. Object speeds were a constant $8.5 \mathrm{dva} / \mathrm{sec}$, reflecting off the edges of the screen. Heading angle was slightly altered on each frame to reduce predictability of object motion. On every video frame $(60 \mathrm{~Hz})$, object direction could be changed by $\mathrm{X}$ degrees, where $-1.15<\mathrm{X}<1.15$ (with initial values randomly assigned from within this range), and with each new frame $\mathrm{X}$ increased or decreased, $-0.57<\Delta \mathrm{X}<$ 0.57 (with the change value randomly chosen within this range). While objects could occlude each other, occlusion was minimized by generating each participant's trials in advance and only retaining those with low object occlusion rates (the lowest $5 \%$ of all trials generated).

Order of the trials was interleaved between the independent motion MOT (Condition 1 Figure 4A) and two conditions using common motion to create pairs (Condition 2 and 3 Figures $4 \mathrm{~B}$ and $4 \mathrm{C}$ ), so that participants completed one trial of each type, repeating the sequence for a total of 60 trials ( 20 trials each). Of the eight squares, four were targets. At the beginning of each trial, the four target squares started out white and switched to black after $2000 \mathrm{~ms}$. Then all the squares moved for a total of $8000 \mathrm{~ms}$. After the movement stopped, participants clicked on the four squares they thought were the targets. 
In the grouping manipulations, displays and motion algorithms were the same as for the original MOT, with the following exceptions. To manipulate performance we linked the movement of 4 of the objects to a second 4 objects (see Suganuma M \& Yokosawa K., 2006 for a similar manipulation): targets were either 2 sets of 2 elements moving together (targets moving together: Target-Target condition) or 1 element from each pair of elements (each target moving with a distractor: Target-Distractor condition). In the grouped conditions, objects were spaced 5.25 dva apart horizontally. In the Target-Distractor condition the position of the target was on the left for 2 of the pairs, and on the right for the other 2 pairs. The groups 'bounced' off the horizontal and vertical sides of the display if either object's position in the subsequent animation frame would place its boundary offscreen.

Statistical analyses-We converted percent correct into a measure of capacity (k), the number of objects tracked or remembered. We used the high threshold guessing model (Hulleman, 2005):

$$
\mathrm{k}=\frac{\mathrm{nc}-\mathrm{t}^{2}}{\mathrm{n}+\mathrm{c}-2 \mathrm{t}}
$$

where $\mathrm{n}=$ total number of elements (always 8 in this study), $\mathrm{t}=$ number of targets to be tracked (always 4 ) and $c=$ the number of targets correctly identified. All statistical analyses used these $\mathrm{k}$ values, though results were the same when percent correct was used.

An initial omnibus ANOVA was done, followed by an analysis of each condition separately. In the two conditions with the objects grouped, our question of interest was whether grouping affects the participants with autism differently from TD individuals. Thus, we first examined these manipulations using repeated measures ANOVAs with Group (autism, TD) and Age (children, adolescents, adults) as between subject factors, and Condition (independent motion, common motion manipulation) as a within subject factor. We then used paired t-tests to compare the original score to the manipulation (i.e., Target-Target or Target-Distractor) in each group separately, with Age as a factor, to see whether performance developed in either group.

\section{Results}

Preliminary omnibus ANOVA: k score or capacity-An initial omnibus repeated measures ANOVA, with Condition (Independent Motion, Target-Target, Target-Distractor) as a within subject factor, and Group (autism, TD) and Age (child, adolescent, adult) as between subjects factors revealed main effects of Condition $(F(1.94,139.87)=189.26, p<$. $001)$ and Group $(\mathrm{F}(1,72)=9.49, \mathrm{p}=.003)$ but not Age $(\mathrm{F}(2,72)=1.87, \mathrm{p}=.15)$. The manipulations in Condition 2 and 3 affected performance as expected, and the group with autism performed more poorly than controls (a pattern evident when each Condition was examined separately: Target-Target, $\mathrm{F}(1,72)=3.55$, $\mathrm{p}=.06$; Target-Distractor, $\mathrm{F}(1,72)=6.16$, $\mathrm{p}=.02)$. Condition interacted significantly with $\operatorname{Group}(\mathrm{F}(1.94,139.87)=3.68, \mathrm{p}=.03)$, though there were no other interactions. Conditions were analyzed separately since performance differed between them across groups.

\section{Main analyses: $\mathbf{k}$ score or capacity in Condition 1}

Condition 1: Independent Motion (Figure 5A): An ANOVA on the $k$ values included the between subjects factors of Group and Age. This analysis revealed a main effect of Group $(\mathrm{F}(1,72)=9.04, \mathrm{p}=.004)$. There was no main effect of $\operatorname{Age}(\mathrm{F}(2,72)=1.55, \mathrm{p}=.22)$, nor an interaction between Group and Age $(\mathrm{F}(2,72)=.03, \mathrm{p}=.97)$. When analyzed separately, neither group displayed significant developmental improvement in MOT (p's > .38). 
Participants with autism had a smaller tracking capacity than TD participants. This difference was stable across age groups.

\section{Main analyses: Effects of common motion (Condition 2 \& 3 ) on $\mathrm{k}$ score}

Condition 2: Target-Target Condition (Figure 5B): We used an ANOVA to examine group differences with the within subject factor of Condition (target-target, independent motion) and the between subject factors of Group and Age. The improvement in the targettarget condition was confirmed by a main effect of Condition $(\mathrm{F}(1,72)=143.71, \mathrm{p}<.001)$; however, there was also a significant Group $\times$ Condition interaction $(F(1,72)=6.35, \mathrm{p}=$. $01)$. This reflected that pairing the targets actually helped participants with autism more than TD participants, but this may reflect ceiling performance (a $K=3.92$ out of 4$)$ in the TD participants. Other than the expected main effect of $\operatorname{Group}(\mathrm{F}(1,72)=8.82, \mathrm{p}=.004)$, with the participants with autism performing more poorly overall, there were no other significant effects or interactions.

A repeated measures ANOVA compared Condition (independent motion, target-target condition) in each group separately, with Age as a between subject factor. This examined whether the effects of the manipulation changed with age in each group. There was a main effect of Condition in participants with and without autism (autism: $F(1,36)=75.81, \mathrm{p}<$. 001; TD participants: $\mathrm{F}(1,36)=73.26, \mathrm{p}<.001)$, showing the Target-Target condition made performance better in both groups but no main effect of Age nor an interaction.

Target-Distractor Condition (Figure 5C): We used an ANOVA to examine group differences with the within subject factor of Condition (target-distractor, independent motion) and the between subject factors of Group and Age. The impact of the configuration was confirmed by a main effect of Condition $(F(1,72)=65.48, \mathrm{p}<.001)$. Other than the expected main effect of Group $(\mathrm{F}(1,72)=9.46, \mathrm{p}=.003)$, with the participants with autism performing more poorly overall, there were no other significant effects or interactions. Pairing the target and distractor had a similar negative impact in participants with and without autism.

A repeated measures ANOVA comparing condition (original MOT, target-distractor condition) was done in each group separately, with Age as a between subject factor, to examine whether the manipulation affected performance in each group separately. There was a main effect of Condition in participants with and without autism (autism: $\mathrm{F}(1,36)=$ 29.31, $\mathrm{p}<.001$; TD participants: $\mathrm{F}(1,36)=36.75$, $\mathrm{p}<.001)$, indicating both groups were affected by the manipulation, but no main effect of Age nor an interaction.

\section{Correlations between individuation measures (subitizing and MOT, Conditions 1, random locations and movement)-We examined whether the $\mathrm{K}$} score reported above on Condition 1, with randomly generated independent movement, was related to the slopes of the subitizing (1 to 3 ) or counting (4 to 7) range, or the subitizing breakpoint as described above. To do so, a partial correlation controlling for full-scale IQ was used, to minimize the possibility of some general intelligence factor influencing the results. Interestingly, the analyses revealed different patterns in the two groups. In the TD participants, there was a trend for the K score on MOT to be significantly related to the slope in the subitizing range $(\mathrm{r}(36)=-.30, \mathrm{p}=.06)$ and the breakpoint $(\mathrm{r}(36)=.32, \mathrm{p}=.054)$ but not the slope in the counting range $(\mathrm{r}(36)=-.02, \mathrm{p}=.90)$. For participants with autism, there was a only a trend for the K score to be related to the slope in the subitizing range $(\mathrm{r}(36)=-$. $28, \mathrm{p}=.09)$, and no relation with the breakpoint $(\mathrm{r}(36)=.22, \mathrm{p}=.19)$. However, there was a significant correlation with the counting range $(\mathrm{r}(36)=-.40, \mathrm{p}=.01)$. While preliminary, these results suggest two relationships. First, typical participants may use a similar mechanism for 
both subitizing and MOT. Second, participants with autism may use a mechanism during MOT that is more similar to serial counting, compared to typical observers. For example, instead of parallel tracking, they might use a more serial switching strategy, or focus on fewer objects.

\section{General Discussion}

These results revealed an unexpected pattern of limitations and intact function in those with autism, as well as insight into how development differs. Both the 'breakpoint' of rapid enumeration and the K scores on MOT indicate that participants with autism represent fewer elements 'simultaneously' than typically developing participants, most often 3 instead of 4 items, consistent with the results of Gagnon and colleagues (2004). We had predicted this pattern on the basis of Gagnon's results and representation of fewer elements in scenes in autism. It is striking that both these tasks show the same pattern as they have disparate task demands, with MOT being a more attention demanding task that requires tracking moving items. Neither group displayed developmental improvement in the number of elements represented, unlike previous studies with younger children (O'Hearn et al., 2005; O'Hearn et al., 2010a; Trick et al., 2005). While this suggests that 'capacity' is set from late childhood on, it also seems likely that a measure with a range as limited as 'capacity' may not be sensitive to late development (in contrast to a continuous measure like RT).

Contrary to our hypothesis, performance in autism was affected to a similar extent as TD participants by grouping information on the enumeration and MOT tasks. These two very different tasks again revealed similar results when modified to study the effects of grouping the elements in an individuation task. In the rapid enumeration task, having the elements in a dice pattern improved the speed of participants with autism more than TD participants, while having the objects grouped as concentric squares slowed performance equally. Results were similar for the MOT task, with no evidence that the participants with autism were less sensitive to the arrangement of elements compared to TD participants, whether the manipulations helped or hurt performance typically. In fact, children with autism tended to be more sensitive to the effects of grouping in the enumeration task, compared to older individuals with autism and the TD participants, though this may reflect their level of performance in original individuation tasks.

While caution is urged when interpreting the children's data, because of the small sample size and cross-sectional design, children with autism appeared to display a unique pattern of visual processing, compared to older individuals with autism. Developmental analyses suggested the grouping of elements in the enumeration task particularly affected children with autism, whether it was an improvement or a decrement in performances. In addition, the slope in the subitizing range suggested that children with autism might have sometimes been counting even in the 'subitizing' range (see also Jarrold \& Russell, 1997). This may indicate increased caution on the part of children with autism, potentially reflecting a similar tendency to the adults with autism in this study, who displayed more accurate performance with 6 and 7 elements than TD adults. Alternately, the counting in children with autism may reflect that it is more difficult for them to 'see' several items simultaneously, and so they default to counting to be accurate.

Another interesting developmental pattern came from our analysis of RTs in the subitizing (1-3) and the counting (5-7) range. While both were impacted by autism, the developmental trajectories of these limitations differed, suggesting distinct etiologies. In TD participants, RT got faster with age in both ranges: in autism, RT became faster with age only in the counting range. The difference between groups in the speed of counting was most evident in childhood, with some 'catch up' by adolescence. Differences in the counting range may 
reflect the difficulties that participants with autism have shifting attention (Williams et al., 2005), and disengaging attention, which is evident in early childhood ("sticky attention"; Landry \& Bryson, 2004). In contrast, group differences in the speed of subitizing became more notable in adulthood, reflecting in part a lack of adolescent development. Other studies also show a lack of development from adolescence to adulthood in autism (Scherf et al., 2008; Rump et al., 2009), including our own (O'Hearn et al., 2010b; O'Hearn et al., 2011b). While it is difficult to identify what these tasks have in common, they all seem to utilize a 'holistic' style of processing, whether it is the representation of faces, scenes or the overall shape that may develop later (Scherf et al., 2009). This development may not occur in autism for biological or experiential reasons, or a combination of both (Maurer, Mondloch \& Lewis, 2007).

The study of individuation (as measured by rapid enumeration and MOT) and the effects of grouping on this skill, adds an important piece to the puzzle of how visual processing differs in autism. Participants with autism were just as sensitive to grouping information as TD participants in this study, conflicting with some of the previous evidence indicating that people with autism are less sensitive to the holistic configuration of visual stimuli (Behrmann et al., 2006 but see also Mottron et al., 2003). Why this discrepancy occurred is unclear, but there are several possibilities. In individuation tasks, even in the grouping conditions, the individual elements must be counted or tracked. This may be an important task difference from other studies, such as face recognition which require a primary focus on the global configuration. For the MOT task, that the grouping manipulation was common motion might be important. Recent work suggests that some grouping factors (e.g., color, shape, orientation) are not processed as 'globally' as others, such as grouping by physical connection or proximity (Franconeri et al., 2009). Instead, grouping occurs because we pay attention only to that feature (Huang \& Pashler, 2007), tuning our visual system to select more 'locally' in feature space. Common fate may be such a grouping factor because the current direction of an object is matched by its pair (Levinthal \& Franconeri, 2011). Thus, the lack of differences between participants with and without autism may reflect that common motion utilizes a fundamentally different grouping mechanism, relative to other measures (e.g. face or pattern recognition) used in past studies.

For both the rapid enumeration and MOT tasks, another potential explanation is that the grouped displays themselves were relatively simple, and differences may become evident only when more complex information needs to be encoded (Minshew et al., 2002).

However, this seems unlikely as other studies with relatively simple displays have reported differential sensitivity to configural information in autism. For instance, with a global-local display of diamonds or squares, Behrmann et al (2006) found group differences in global processing in adults with autism. The group differences in autism evident on this task may reflect that their microgenetic task directly compares the precedence of global and local information, pitting them against each other, unlike ours that measures individuation of objects. In addition, the arrangement of elements in our stimuli (dice patterns, etc) might lend themselves to specific strategies, unlike a more reflexive task like face recognition. Together with the previous literature, this work indicates that multiple processes support holistic processing, including individuation and grouping tested here; these processes may develop independently and be differentially vulnerable. Further empirical work is needed, with results from autism potentially helping to delineate what 'holistic' processes are related typically.

Since we found limitations - not superior skill - in individuation in autism, any visual search advantage for participants with autism is probably not due to an ability to individuate more objects simultaneously. This conclusion is consistent with results indicating the amplified ability on visual search tasks in autism is linked to the ability to discriminate 
targets, not to see more elements (O'Riordan \& Plaisted, 2001). Participants with autism actually seem to 'see' feweritems at once, although they may be able to encode more details of those objects and this may help them to discriminate targets from distracters better than TD participants. These disparate abilities - to see multiple objects and to encode their features - have been linked to distinct brain regions in the parietal lobe (Xu \& Chun, 2009). A decreased individuation capacity has been reported in several other developmental disorders that impact the parietal lobe (Turners syndrome, Bruandet et al., 2004; Williams syndrome, O'Hearn et al., 2011a; 22q11.2 delection syndrome, Simons et al., 2005). Children with these disorders can enumerate and track objects, which is notable, but do appear to have a smaller capacity (Ansari \& Karmiloff-Smith, 2002; Bruandet et al., 2004; O'Hearn et al., 2005, 2010a, 2011a; Simon et al., 2005). There may be multiple ways to impact individuation ability over development, across such disparate disorders. Atkinson and Braddick (2011) suggest that the dorsal stream in the parietal lobe is particularly susceptible to insult over development, and Spencer et al., 2000 suggest this may be true in autism.

Together, these general differences in how participants with autism may see the world slightly fewer elements, slower serial processes, and less sensitivity to parallel/holistic processes that mature into adulthood - could undermine the representation of multiple elements in several ways, impacting how people with autism do important visual tasks, such as interpreting social scenes. While this work on individuation links together enumeration and MOT, it is unclear what mechanism leads to the same pattern of between groups differences on both tasks. While it could be a perceptual mechanism like Pylyshyn's indexes (discussed in O'Hearn et al., 2010), it might be something more akin to the 'attentional management', the ability to know where to look in a scene (Rensink, 2002). That the arrangement of the elements on individuation tasks impacts people with autism is important, because it suggests that people with autism could keep track of more elements, through topdown knowledge (i.e., dice patterns) or perceptual grouping (i.e., common movement). Our evidence that there is substantial development from childhood to adolescence in autism also has important pragmatic ramifications and suggests that the timing of visual interventions might be important. What continues to interest us is how these basic perceptual differences might affect the ability to interpret complex scenes in autism, and what the developmental course of these abilities both typically and in autism indicates about the mechanisms of development.

\section{Acknowledgments}

This work was supported by Autism Speaks Grant 04593 (BL), NIMH 5 R01 MH067924 (BL), NIMH K01 MH081191 (KO), NSF CAREER 1056730 (SF). It was also supported by HD055748 (PI Minshew) from the Eunice Kennedy Shriver National Institute of Child Health \& Human Development. The content is solely the responsibility of the authors and does not necessarily represent the official views of the National Institutes of Health. We thank Elizabeth Schroer and Andrew Lynn for help with the manuscript, and Jonathon Steinhart and Allan Sampson for help with the statistics. We are very grateful to the participants and their families, and the staff at the Center for Excellence in Autism Research (CeFAR).

\section{References}

Abrams L, Jennings DT. VoiceRelay: voice key operation using visual basic. Behavior Research Methods Instruments and Computers. 2004; 36:771-777.

Alvarez GA, Franconeri SL. How many objects can you track?: Evidence for a resource-limited attentive tracking mechanism. Journal of Vision. 2007; 7:1-10.

Annaz D, Remington A, Milne E, Coleman M, Campbell R, Thomas MS, Swettenham J. Development of motion processing in children with autism. Developmental Science. 2010; 13:826-38. [PubMed: 20977554] 
Ansari D, Karmiloff-Smith A. Atypical trajectories of number development: A neuroconstructivist perspective. Trends in Cognitive Sciences. 2002; 6:511-516. [PubMed: 12475711]

Atkinson J, Braddick OJ. From genes to brain development to phenotypic behavior: "dorsal-stream vulnerability" in relation to spatial cognition, attention, and planning of actions in Williams syndrome (WS) and other developmental disorders. Progress in Brain Research. 2011; 189:261283. [PubMed: 21489394]

Behrmann M, Avidan G, Leonard GL, Kimchi R, Luna B, Humphreys K, et al. Configural processing in autism and its relationship to face processing. Neuropsychologia. 2006; 44:110-129. [PubMed: 15907952]

Brosnan MJ, Scott FJ, Fox S, Pye J. Gestalt processing in autism: failure to process perceptual relationships and the implications for contextual understanding. Journal of Child Psychology and Psychiatry. 2004; 45:459-469. [PubMed: 15055366]

Brown WE, Kesler SR, Eliez S, Warsofsky IS, Haberecht M, Reiss AL. A volumetric study of parietal lobe subregions in Turner syndrome. Developmental Medicine and Child Neurology. 2004; 46:607609. [PubMed: 15344520]

Bruandet M, Moko N, Cohen L, Dehaene S. A cognitive characterization of dyscalculia in Turner syndrome. Neuropsychologia. 2004; 42:288-298. [PubMed: 14670569]

Carey S, Xu F. Infants' knowledge of objects: beyond object files and object tracking. Cognition. 2001; 80:179-213. [PubMed: 11245844]

Chesney D, Haladjian H. Evidence for a shared mechanism used in multiple-object tracking and subitizing. Attention, Perception, \& Psychophysics. 2011; 73:2457-2480.

Chi MT, Klahr D. Span and rate of apprehension in children and adults. Journal of Experimental Child Psychology. 1975; 19:434-439. [PubMed: 1236928]

Comtois, R. VisionShell PPC [Software libraries]. Author; Cambridge, MA: 2004.

Cowan N. The magical number 4 in short-term memory: a reconsideration of mental storage capacity. Behavioral and Brain Sciences. 2001; 24:87-114. [PubMed: 11515286]

Culham JC, Cavanagh P, Kanwisher N. Attention response functions: characterizing brain areas using fMRI activation during parametric variations of attentional load. Neuron. 2001; 32:737-745. [PubMed: 11719212]

Dakin S, Frith U. Vagaries of visual perception in autism. Neuron. 2005; 48:497-507. [PubMed: 16269366]

Ecker C, Suckling J, Deoni SC, Lombardo MV, Bullmore ET, Baron-Cohen S, Catani M, Jezzard P, Barnes A, Bailey AJ, Williams SC, Murphy DG, MRC AIMS Consortium. Brain anatomy and its relationship to behavior in adults with autism spectrum disorder: A multicenter magnetic resonance imaging study. Archives of General Psychiatry. 2012; 69:195-209. [PubMed: 22310506]

Farran EK, Brosnan MJ. Perceptual grouping abilities in individuals with autism spectrum disorder; exploring patterns of ability in relation to grouping type and levels of development. Autism Research. 2011; 4:283-292. [PubMed: 21608137]

Falter CM, Grant KC, Davis G. Object-based attention benefits reveal selective abnormalities of visual integration in autism. Autism Research. 2010; 3:128-36. [PubMed: 20578070]

Feigenson L, Carey S. On the limits of infants' quantification of small object arrays. Cognition. 2005; 97:295-313. [PubMed: 16260263]

Feigenson L, Dehaene S, Spelke E. Core systems of number. Trends in Cognitive Sciences. 2004; 8:307-14. [PubMed: 15242690]

Fletcher-Watson S, Leekam SR, Turner MA, Moxon L. Do people with autistic spectrum disorder show normal selection for attention? Evidence from change blindness. British Journal of Psychology. 2006; 97:537-554. [PubMed: 17018188]

Franconeri SL, Bemis DK, Alvarez GA. Number estimation relies on a set of segmented objects. Cognition. 2009; 113:1-13. [PubMed: 19647817]

Freeth M, Chapman P, Ropar D, Mitchell P. Do gaze cues in complex scenes capture and direct the attention of high functioning adolescents with ASD? Evidence from eye-tracking. Journal of Autism \& Developmental Disorders. 2010; 40:534-547. [PubMed: 19904597] 
Freire A, Lee K, Symons L. The face-inversion effect as a deficit in the encoding of configural information: direct evidence. Perception. 2000; 29:159-170. [PubMed: 10820599]

Gagnon L, Mottron L, Bherer L, Joanette Y. Quantification judgement in high functioning autism: superior or different? Journal of Autism \& Developmental Disorders. 2004; 34:679-689. [PubMed: 15679187]

Glazebrook C, Gonzalez D, Hansen S, Elliott D. The role of vision for online control of manual aiming movements in persons with autism spectrum disorders. Autism. 2009; 13:411-433. [PubMed: 19535469]

Happe F. Autism: cognitive deficit or cognitive style? Trends in Cognitive Sciences. 1999; 3:216-222. [PubMed: 10354574]

Hua X, Thompson PM, Leow AD, Madsen SK, Caplan R, Alger JR, O'Neill J, Joshi K, Smalley SL, Toga AW, Levitt JG. Brain growth rate abnormalities visualized in adolescents with autism. Human Brain Mapping. Oct 20.2011 2011.

Huang L, Pashler H. A boolean map theory of visual attention. Psychological Review. 2007; 114:599_ 631. [PubMed: 17638498]

Hulleman J. The mathematics of multiple object tracking: from proportions correct to number of objects tracked. Vision Research. 2005; 45:2298-2309. [PubMed: 15924943]

Jarrold C, Russell J. Counting abilities in autism: possible implications for central coherence theory. Journal of Autism and Developmental Disorders. 1997; 27:25-37. [PubMed: 9018580]

Kahneman D, Treisman A, Gibbs BJ. The reviewing of object files: Object-specific integration of information. Cognitive Psychology. 1992; 24:175-219. [PubMed: 1582172]

Kaufman EL, Lord MW, Reese TW, Volkmann J. The discrimination of visual number. American Journal of Psychology. 1949; 62:498-525. [PubMed: 15392567]

Kimchi R, Hadad B, Behrmann M, Palmer SE. Microgenesis and ontogenesis of perceptual organization: evidence from global and local processing of hierarchical patterns. Psychological Science. 2005; 16:282-290. [PubMed: 15828975]

Kuschner ES, Bodner KE, Minshew NJ. Local vs. global approaches to reproducing the Rey Osterrieth Complex Figure by children, adolescents, and adults with high-functioning autism. Autism Research. 2009; 2:348-358. [PubMed: 19950303]

Landry R, Bryson SE. Impaired disengagement of attention in young children with autism. Journal of Child Psychology and Psychiatry and Allied Discipline. 2004; 45:1115-1122.

Leslie AM, Xu F, Tremoulet PD, Scholl BJ. Indexing and the object concept: developing 'what' and 'where' systems. Trends in Cognitive Sciences. 1998; 2:10-18. [PubMed: 21244957]

Levinthal BR, Franconeri SL. Common-Fate Grouping as Feature Selection. Psychological Science. 2011; 22:1132-1137. [PubMed: 21828350]

Lord C, Risi S, Lambrecht L, Cook EH Jr. Leventhal BL, DiLavore PC, et al. The autism diagnostic observation schedule-generic: a standard measure of social and communication deficits associated with the spectrum of autism. Journal of Autism and Developmental Disorders. 2000; 30:205-223. [PubMed: 11055457]

Lord C, Rutter M, Couteur AL. Autism diagnostic interview-revised: a revised version of a diagnostic interview for caregivers of individuals with possible pervasive developmental disorders. Journal of Autism and Developmental Disorders. 1994; 24:659-685. [PubMed: 7814313]

Loth E, Gómez CJ, Happé F. Detecting changes in naturalistic scenes: contextual inconsistency does not influence spontaneous attention in high-functioning people with autism spectrum disorder. Autism Research. 2008; 1:179-188. [PubMed: 19360664]

Luck SJ, Vogel EK. The capacity of visual working memory for features and conjunctions. Nature. 1997; 390:279-281. [PubMed: 9384378]

Luna B, Doll S, Hegedus SJ, Minshew N, Sweeney J. Maturation of Executive Function in Autism. Biological Psychiatry. 2007; 61:474-481. [PubMed: 16650833]

Mandler G, Shebo BJ. Subitizing: An analysis of its component processes. Journal of Experimental Psychology: General. 1982; 111:1-22. [PubMed: 6460833]

Maylor EA, Watson DG, Hartley EL. Effects of distraction on visual enumeration in children and adults. Developmental Psychology. 2012; 47:1440-1447. [PubMed: 21744947] 
Maurer D, Mondloch CJ, Lewis TL. Sleeper effects. Developmental Science. 2007; 10:40-7. [PubMed: 17181698]

Meyer-Lindenberg A, Kohn P, Mervis CB, Kippenhan JS, Olsen RK, Morris CA, et al. Neural basis of genetically determined visuospatial construction deficit in Williams syndrome. Neuron. 2004; 43:623-31. [PubMed: 15339645]

Milne E, Swettenham J, Hansen P, Campbell R, Jeffries H, Plaisted K. High motion coherence thresholds in children with autism. Journal of Child Psychology and Psychiatry and Allied Discipline. 2002; 43:255-63.

Minshew NJ, Sweeney J, Luna B. Autism as a selective disorder of complex information processing and underdevelopment of neocortical systems. Molecular Psychiatry. 2002; 7:S14-S15. [PubMed: 12142935]

Mitroff SR, Scholl BJ, Wynn K. The relationship between object files and conscious perception. Cognition. 2005; 96:67-92. [PubMed: 15833307]

Mottron L, Burack JA, Iarocci G, Belleville S, Enns JT. Locally oriented perception with intact global processing among adolescents with high-functioning autism: evidence from multiple paradigms. Journal of Child Psychology and Psychiatry and Allied Disciplines. 2003; 44:904-913.

Mottron L, Dawson M, Soulieres I, Hubert B, Burack J. Enhanced perceptual functioning in autism: an update, and eight principles of autistic perception. Journal of Autism and Developmental Disorder. 2006; 36:27-43.

Navon D. Forest before trees: The precedence of global features in visual perception. Cognitive Psychology. 1977; 9:353-383.

O'Hearn K, Hoffman JE, Landau B. Developmental profiles for multiple object tracking and spatial memory: Normally developing preschoolers and people with Williams syndrome. Developmental Science. 2010a; 13:430-440. [PubMed: 20443964]

O'Hearn K, Hoffman JE, Landau B. Small subitizing range in people with Williams syndrome. Visual Cognition. 2011a; 19:289-312. [PubMed: 21516186]

O'Hearn K, Lakusta L, Schroer E, Minshew N, Luna B. Deficits in adults with autism spectrum disorders when processing multiple objects in dynamic scenes. Autism Research. 2011b; 4:132142. [PubMed: 21254449]

O'Hearn K, Landau B, Hoffman JE. Multiple object tracking in people with Williams syndrome and in normally developing children. Psychological Science. 2005; 16:905-912. [PubMed: 16262778]

O'Hearn K, Schroer E, Minshew N, Luna B. Lack of developmental improvement in face recognition during adolescence in Autism Spectrum Disorders. Journal of Neuropsychologia. 2010b; 48:395560 .

O'Riordan M, Plaisted K. Enhanced discrimination in autism. The Quarterly Journal of Experimental Psychology. 2001; 54:961-979. [PubMed: 11765744]

Piazza M, Giacomini E, Le Bihan D, Dehaene S. Single-trial classification of parallel pre-attentive and serial attentive processes using functional magnetic resonance imaging. Proceedings Royal Society London B Biological Sciences. 2003; 270:1237-45.

Pylyshyn ZW. Situating vision in the world. Trends Cognitive Science. 2000; 4:197-207.

Pylyshyn ZW, Storm RW. Tracking multiple independent targets: Evidence for a parallel tracking mechanism. Spatial Vision. 1988; 3:179-197. [PubMed: 3153671]

Quinn P, Bhatt R. Transfer and Scaffolding of Perceptual Grouping Occurs Across Organizing Principles in 3- to 7-Month-Old Infants. Psychological Science. 2009; 20:933-938. [PubMed: 19538436]

Remington A, Swettenham J, Campbell R, Coleman M. Selective attention and perceptual load in autism spectrum disorder. Psychological Science. 2009; 20:1388-93. [PubMed: 19843262]

Rensink RA. Change detection. Annual Review of Psychology. 2002; 53:245-277.

Revkin SK, Piazza M, Izard V, Cohen L, Dehaene S. Does subitizing reflect numerical estimation? Psychological Science. 2008; 19:607-614. [PubMed: 18578852]

Rump KM, Giovannelli JL, Minshew NJ, Strauss MS. The Development of Emotion Recognition in Individuals With Autism. Child Development. 2009; 80:1434-1447. [PubMed: 19765010] 
Scherf KS, Behrmann M, Kimchi R, Luna B. Emergence of global shape processing continues through adolescence. Child Development. 2009; 80:162-177. [PubMed: 19236399]

Scherf KS, Luna B, Kimchi R, Minshew N, Behrmann M. Missing the big picture: impaired development of global shape processing in autism. Autism Research. 2008; 1:114-129. [PubMed: 19360658]

Scholl BJ, Pylyshyn ZW, Feldman J. What is a visual object? Evidence from target merging in multiple object tracking. Cognition. 2001; 80:159-177. [PubMed: 11245843]

Shah A, Frith U. An islet of ability in autistic children: a research note. Journal of Child Psychology and Psychiatry and Allied Disciplines. 1983; 24:613-620.

Shah A, Frith U. Why do autistic individuals show superior performance on the block design task? Journal of Child Psychology and Psychiatry. 1993; 34:1351-64. [PubMed: 8294523]

Simmons DR, Robertson AE, McKay LS, Toal E, McAleer P, Pollick FE. Vision in autism spectrum disorders. Vision Research. 2009; 49:2705-2735. [PubMed: 19682485]

Simon TJ, Bearden CE, Mc-Ginn D, Zackai E. Visuospatial and Numerical Cognitive Deficits in Children with Chromosome 22q11.2 Deletion Syndrome. Cortex. 2005; 41:145-155. [PubMed: 15714897]

Spencer J, O'Brien J, Riggs K, Braddick O, Atkinson J, Wattam-Bell J. Motion processing in autism: evidence for a dorsal stream deficiency. Neuroreport. 2000; 11:2765-7. [PubMed: 10976959]

Starkey P, Cooper RG Jr. The development of subitizing in young children. British Journal of Developmental Psychology. 1995; 13:399-420.

Suganuma M, Yokosawa K. Grouping and trajectory storage in multiple object tracking: impairments due to common item motions. Perception. 2006; 35:483-495. [PubMed: 16700291]

Svenson O, Sjöberg K. Subsidizing and counting processes in young children. Scandinavian Journal of Psychology. 1978; 19:247-250.

Townsend, JT.; Ashby, FG. Stochastic modeling of elementary psychological processes. Cambridge University Press; Cambridge: 1983.

Trick LM, Enns JT, Brodeur DA. Lifespan changes in visual enumeration: The number discrimination task. Developmental Psychology. 1996; 32:925-932.

Trick LM, Jaspers-Fayer F, Sethi N. Multiple-object tracking in children: The "Catch the Spies" task. Cognitive Development. 2005; 20:373-387.

Trick LM, Pylyshyn ZW. Why are small and large numbers enumerated differently? A limitedcapacity preattentive stage in vision. Psychological Review. 1994; 101:80-102. [PubMed: 8121961]

Wechsler, D. Wechsler Abbreviated Scale of Intelligence. The Psychological Corporation; San Antonio, TX: 1999.

Williams DL, Goldstein G, Minshew N. Impaired memory for faces and social scenes in autism: clinical implications of memory dysfunction. Archives Clinical Neuropsychology. 2005; 20:1-15.

Wynn K. Addition and subtraction by human infants. Nature. 1992; 358:749-750. [PubMed: 1508269]

Xu Y, Chun MM. Dissociable neural mechanisms supporting visual short-term memory for objects. Nature. 2006; 440:91-95. [PubMed: 16382240]

$\mathrm{Xu}$ Y, Chun MM. Selecting and perceiving multiple visual objects. Trends in Cognitive Sciences. 2009; 13:167-174. [PubMed: 19269882] 
Figure $1 \mathrm{~A}$
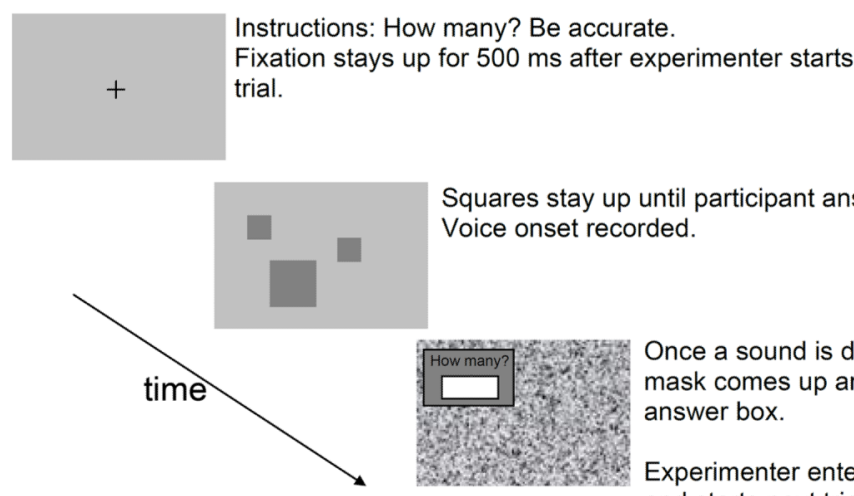

Squares stay up until participant answers. Voice onset recorded.
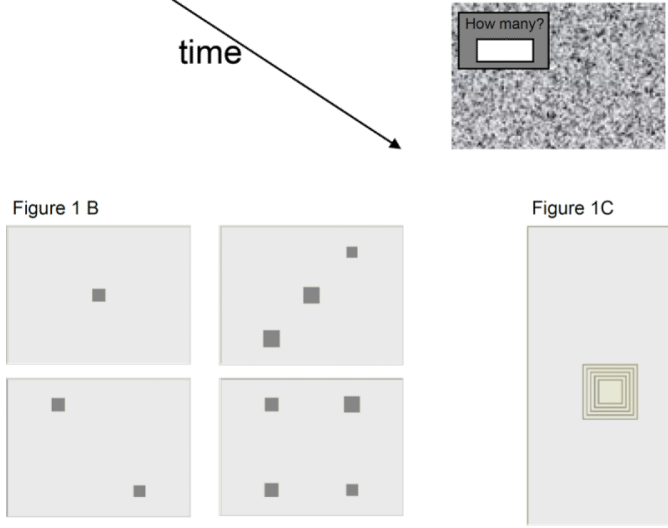

Once a sound is detected, a mask comes up and then answer box.

Experimenter enters answer and starts next trial.

Figure 1.

Rapid enumeration methods. A. Illustration of the enumeration task. Participants fixate, then the display appears and participants answer as rapidly as they can while maintaining accuracy. A microphone records the timing. B and C. Illustration of the grouping manipulations in the enumeration task. B. Examples of Dice configurations C. An example of a Concentric configuration 


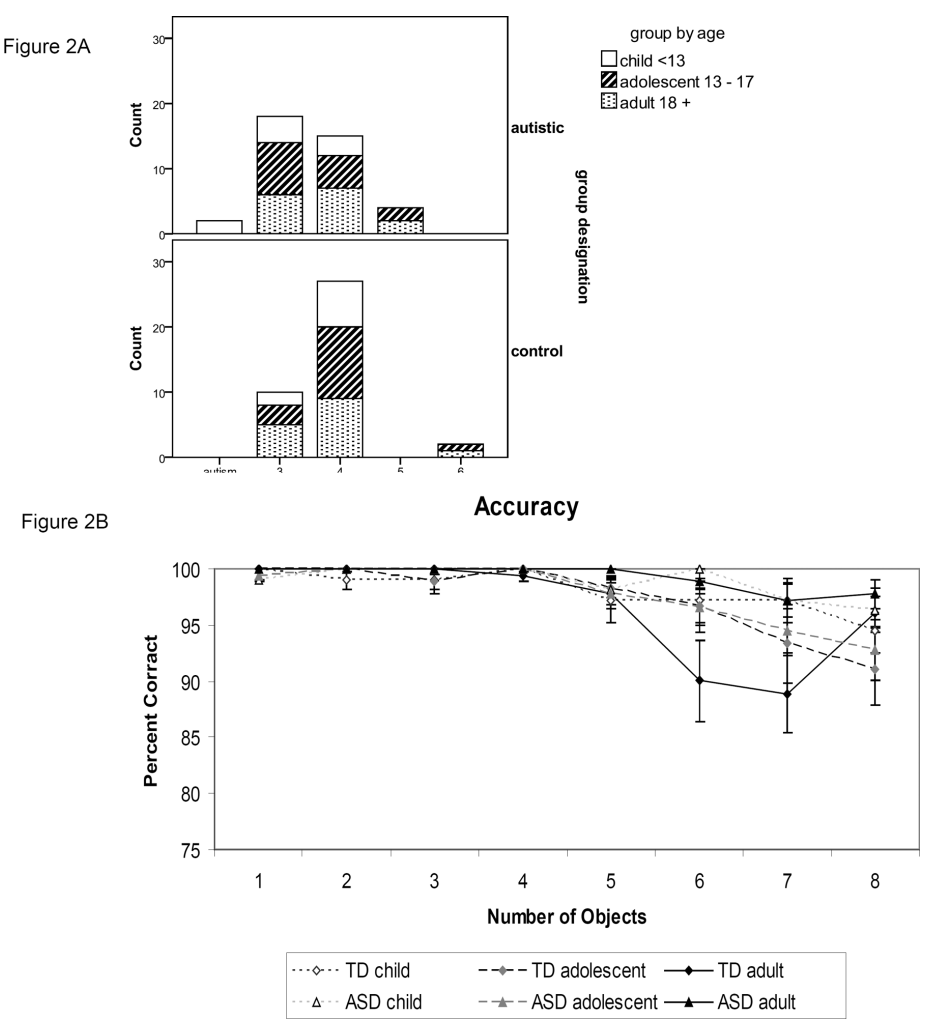

Figure 2.

Subitizing results. A. Histogram indicating breakpoint, how many objects an individual subitized, with typically developing participants on the bottom and participants with autism on the top. B. Accuracy in all groups. 

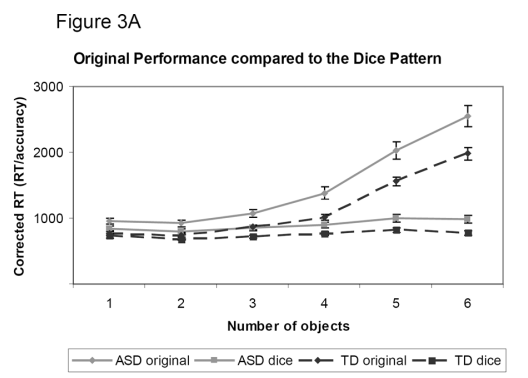

Figure $3 \mathrm{C}$

Original Performance compared to the Concentric Pattern

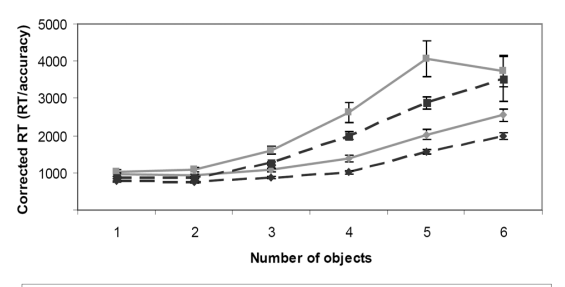

$\longrightarrow$ ASD original $\longrightarrow$-ASD concentric $-\leftarrow$ TD original $-\leftarrow$ TD concentric
Figure 3B

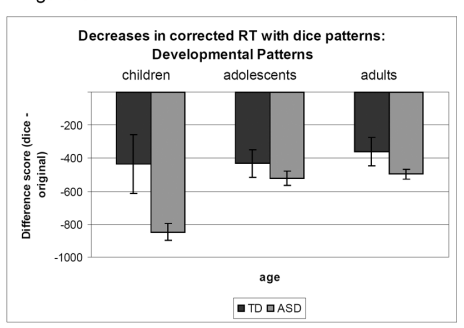

Figure 3D

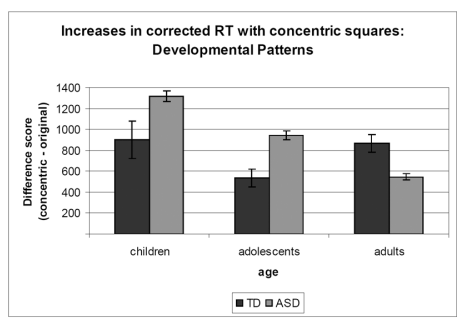

Figure 3.

The effects of the grouping manipulations on the rapid enumeration task. A \& B. Dice configuration. A. Performance with random and dice arrangements, with object number on the $\mathrm{x}$ axis. B. Performance collapsed across object number, with Age on the $\mathrm{x}$ axis, in participants with and without autism. C \& D. Concentric configuration. C. Performance with random and concentric arrangements, with object number on the $\mathrm{x}$ axis. D. Performance collapsed across object number, with Age on the $\mathrm{x}$ axis, in participants with and without autism. Note that the scale on the y axis differs across the dice and concentric manipulations. Error bars are standard error of the mean. 


\section{Multiple Object Tracking (MOT)}
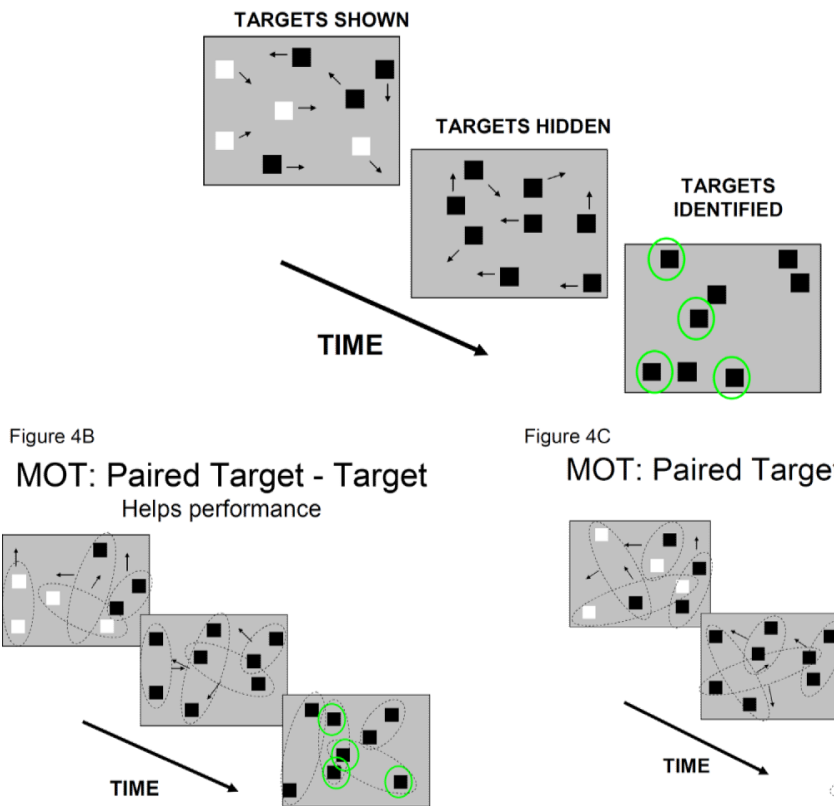

Figure $4 \mathrm{C}$
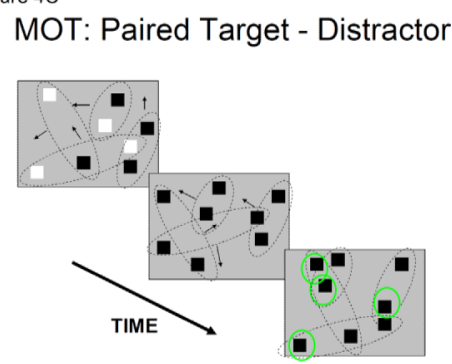

Figure 4.

Multiple Object Tracking (MOT) methods. A. Illustration of MOT. Four of the eight objects change color to indicate that they are targets. They then go back to the original color, and move on independent trajectories. The objects then stop and participants identify the objects that were originally cues as targets. B \& C. Illustration of the grouping manipulations used in the MOT task. B. Target-Target. C. Target-Distractor. 
Multiple Object Tracking - K score
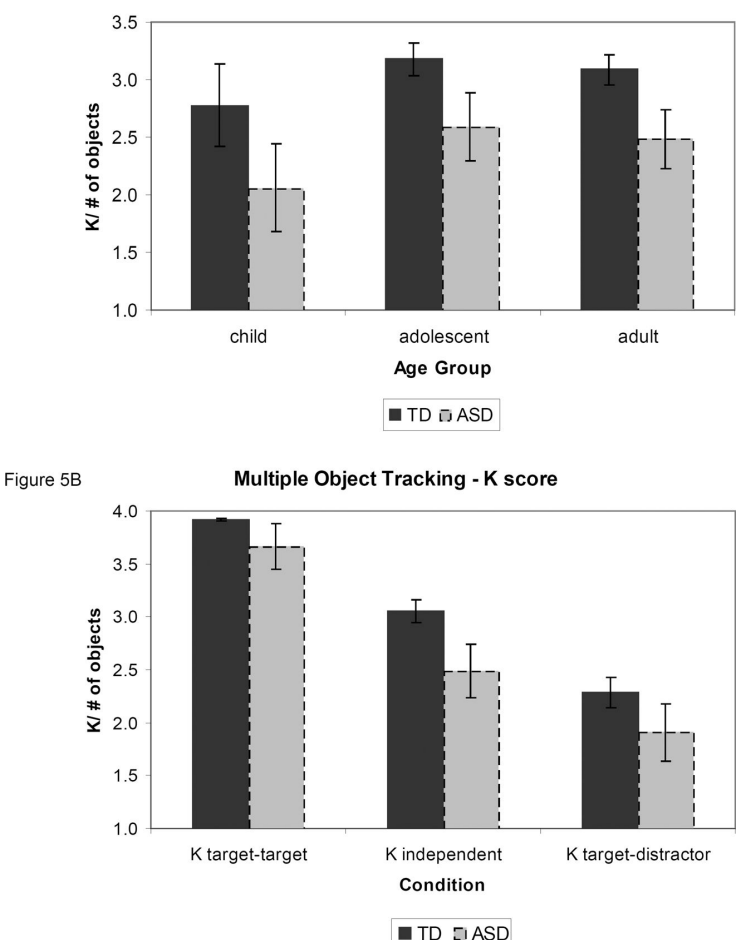

Figure 5.

Multiple Object Tracking (MOT) results. A. K scores on the MOT task with independent motion across age. B. Effects of grouping manipulations on MOT, collapsed across Age. 
